\title{
Una Realidad Aparte: lo verosímil en el EZLN
}

\author{
José Guadalupe Figueroa Soria \\ Facultad de Ciencias Politicas y Administración Pública, UAEM
}

\section{Introducción}

La nota a ocho columnas de la mañana del domingo 2 de enero de 1994, informaba que había una "Sublevación en Chiapas", que se emitía una "Declaración de Guerra al Ejercito Mexicano" y que un tal Marcos declaraba por medio de un comunicado que "esta no es una guerrilla que pega y huye, sino pega y avanza” (La Jornada, 2/1/94).

De inmediato nos su surgieron las preguntas y las dudas; ¿qué pasa en este país?, ¿qué pasa en Chiapas?, ¿qué -al final de cuentas- nos ha estado pasando? Además de cuestionar- nos acerca de quiénes eran esos locos que se denominaban guerrilleros.

La realidad que se desayunaba, hasta ese momento, nos arrojó de bruces contra esa otra realidad nacional olvidada, dejada de lado ante la inminencia de la bonanza; para así despertamos del prolongado letargo que significaba el arribo por la puerta grande al primer mundo, o al menos de lo dicho por quienes se empeñaron en hacemos creer que eso sucedería con la entrada en vigencia del Tratado de Libre Comercio (T.L.C.), y del supuesto bienestar que ello significaría para el desarrollo futuro del país.

Para algunos, la indigestión fue grande al pedir su desayuno tipo americano; para otros, significó un retorno a la conciencia aplazada durante más de cinco siglos de negación, rechazo y discriminación de una cultura, que por lo demás ha sido una de las tres bases históricas de nuestro sustento como nación. Los indígenas se salieron del huacal y exigían su derecho a ser escuchados, su derecho a ser oídos, sencillamente su derecho a ser.

Pero aquí se presentó la sorpresa; ya no se trata de aquellos indios ignorantes con manta y sombrero como salidos de las películas épicas de la revolución; ya no se trata, tampoco, de aquellos indios folklóricos que vemos como si fueran cromos en las revistas de turismo; mucho menos de los inditos pintorescos que complementan el paisaje del México rural. Ahora se trata de un indigenismo posmoderno que sabe utilizar los medios de comunicación, que sabe qué decir frente a las cámaras y micrófonos y que apela a la discusión 
con las distintas fuerzas de poder en un diálogo de tú a tú, para construir la interpretación de esa otra realidad que ahí se manifestó.

Ya lo decía Marcos cuando precisaba que "los sofistica- dos medios de comunicación que poseemos se pueden con- seguir en cualquier tienda de artículos de importación del país" (Marcos, 1994).

Esto es precisamente lo que se quiere abordar con este breve ensayo. Analizar las estrategias de comunicación del Ejército Zapatista de Liberación Nacional (E.Z.L.N.) y con las cuales se motivaron el constructo de un imaginario colectivo distinto, en la medida en que han podido llegar a concretar en la gente un verosímil perfecto de la realidad, verosímil proveniente de un grupo no contemplado por la sociedad civil, no considerado por la decisión gubernamental y no pensado como posible por la intelectualidad mexicana.

\section{Aproximaciones Teóricas: acerca del imaginario}

Una revisión de los diferentes comunicados que Marcos envió desde los primeros días del alzamiento, y en especial de las respuestas a las cartas de apoyo que, desde diversos puntos y organizaciones se solidarizaron con el movimiento, vemos claramente que una constante es, después del saludo, abordar los temas de un modo familiar, con un lenguaje no coloquial ni panfletario, sino con un lenguaje cargado de simbolismos y signos reconocibles en el imaginario colectivo de un pueblo que habla sin el diccionario de la Real Academia de la Lengua Española en la mano, que habla sin la retórica propia de aquellos que históricamente han sido los poderosos, los verdugos los responsables de la pérdida de la pluralidad cultural mexicana.

De acuerdo con esto, vamos a entender aquí por imaginario al conjunto de "los productos de la función significan- te" (Colombo, 1993: 17), concepto al que los teóricos le asignan diferentes niveles de explicación, según al ámbito al que haga referencia. De este modo, podemos encontrar un imaginario efectivo que tiene que ver con la construcción de mitos, ideologías, creencias, religiones, paradigmas interpretativos del mundo; y un imaginario radical, asociado a la imagen articulada con la significación, dentro de un sistema simbólico dado.

Quiere decirse con ello, que el imaginario configura el vehículo sensible en la constitución del signo, portador a su vez de la función significante o simbólica. Esta materialidad, del signo actúa como mediación entre la apropiación y la re-apropiación de los significados y la práctica colectiva, lo cual se traduce en la parte orientadora al momento de interpretar la realidad 
humana, es decir, la construcción de los verosímiles que resultan de la significación de la práctica colectiva cotidiana.

Así lo ha hecho Marcos al poner en circulación los contenidos de sus comunicados. Analicemos: nos dice en el Viento primero -el de arriba- que narra cómo el supremo gobierno se enterneció con la miseria indígena de Chiapas y tuvo a bien dotar a la ciudad de hoteles, cárceles, cuarteles y un aeropuerto militar. Y que narra también cómo la bestia se alimenta de la sangre de este pueblo, y otros infelices y desdichados sucesos. (Marcos, 1992)

En esta introducción al documento titulado "Chiapas: el sureste en dos vientos, una tormenta y una profecía”, Marcos amarra esos productos de la función significante en algo que será re-apropiado por lo social. Al emplear un lenguaje de uso común, con palabras tales como supremo gobierno, se enterneció y otros infelices y desdichados sucesos, de entre otras, está asumiendo que dichas palabras ya cuentan con una significación por parte del imaginario colectivo, es decir, que ya son puente entre el signo material de una cosmovisión y la significación que da sentido al quehacer cotidiano.

Cuando él retorna éstas palabras dentro de su discurso, se verifica una mediación significativa, que tiene como formalidad última una re-apropiación que oriente hacia otra manera de interpretar la realidad.

¿Qué se quiere decir con todo esto? Que Marcos apela a otro uso de los medios (siendo en este caso primariamente al uso del lenguaje), para buscar que ello se convierta en vehículo de la constitución del signo, lo que a su vez conducirá necesariamente a una función simbólica a través de su mirada.

Aquí nos enfrentamos con un concepto que es fundamental tratar de definir, y que se refiere al problema del "otro", de "lo otro"; ya que el discurso instaurado por Marcos tiene que ver en gran medida con la cosmovisión de una interpretación "otra" de las cosas, de lo cultural, de lo cotidiano, y no con lo instaurado como verdadero e inamovible desde las prácticas institucionales que rigen la sociedad.

Consideramos a manera de espejo la definición de ese "otro", de ese comprender la función significante del que se confronta con lo "uno", y del que Umberto Eco se expresa del siguiente modo al decir que "el espejo es un fenómeno-umbral, que marca los limites entre imaginario y simbólico" (Eco, 1988: 12). En el mismo sentido habla Marcos, al establecer por ejemplo que" ¿Nuestros muertos, tan mayoritariamente muertos, tan democráticamente muertos de pena porque nadie hacía nada, porque todos los muertos, nuestros muertos, se iban así nomás, sin que nadie dijera, por fin, el iya basta! que devolviera a esas muertes su sentido, sin que nadie pidiera a los muertos de siempre, nuestros muertos, que regresaran a morir otra vez pero ahora para vivir?" (Marcos, 1994). 
Son los límites de ese umbral de la conciencia y del imaginario colectivo, en la relación dialéctica indígena-no indígena que la mayoría de la población, las autoridades y los dueños de los capitales se empeñaban en negar, sólo dotándole, en el mejor de los casos, con un significado de simple cohabitante de este territorio, por no decir piezas de museo en vías de extinción.

Nuestros muertos, que devolviera a esas muertes su sentido, son ejemplos de expresiones precisas y preciosas del manejo del lenguaje en sus dos formas de funcionamiento: por una parte, la conformación de mitologías e ideologías que en él se han incorporado, y que ahora refleja convirtiéndose en espejo de esa realidad y, la otra, que tiene que ver con la incorporación de valores inculcados y aceptados en comunidad, nuestros muertos festivos que trascienden la interpretación de la vida.

Ante este primer nivel de análisis, Marcos ya tiene puntos ganados a su favor para considerarlo como un comunicador en toda la extensión de la palabra. Pero con ello no basta, se hace necesario comprender cómo ese discurso fue incorporado a los medios masivos, dado que en la medida que éste circulara masivamente, mayor sería su incorporación en el imaginario colectivo.

Se aborda, entonces, la imagen producida del E.Z.L.N. desde dos puntos de vista: siendo uno de ellos desde el periodístico y el otro desde el televisivo, en el sentido de que esas imágenes respetaron tanto "su función de señuelo para cazar al lector (como) hasta la cognoscitiva para mejor comprender la -narración- de las noticias" (Vilches, 1987:14).

Asimismo, para los fines de éste ensayo se tomaron en cuenta a ambos medios, por ser unos de los de mayor presencia en la sociedad, y en virtud también de que cuentan con mayor penetración ante los diversos estratos sociales. Uno, elegida La Jornada un tanto en razón de que fue de los medios que tuvieron acceso autorizado por el E.Z.L.N. para cubrir y entrar a la zona del conflicto, así como por su característica de contener artículos en profundidad que apoyan la conformación de opiniones; y el otro, las principales instituciones televisivas de México (Televisa y Televisión Azteca), por su alta audiencia nacional y por la capacidad técnica y humana que tienen para producir la inmediatez- informativa, así como por su supuesta objetividad, que les viene dada gracias a la presentación de imágenes generadas directamente desde le lugar de los hechos. Aunque aquí cabe la salvedad de que Televisa fue de los medios vetados por el zapatismo ante su parcialidad de informador y su comprobado sesgo al ofrecer una clara tendencia en favor de las instituciones establecidas. 


\section{Aproximaciones Teóricas: las Imágenes.}

Se sabe que la imagen periodística, comúnmente llamada la foto de prensa, es un producto determinado por las pro-piedades técnicas y por las leyes de la percepción visual. Pero la visión que el lector tiene del mundo a través de ella, no es la de un registro mecánico de objetos diversos, sino la de la captación de las estructuras significativas que en ella circulan.

Se trata de la transmisión de un valor ideológico y de un valor simbólico; el primero viene dado al atribuírsele determinados significados a las condiciones perceptivas de los elementos que se combinan en su superficie formal, en tanto que el segundo porque suscita categorías universales basadas en elementos antagónicos (p.e. la dialéctica entre lo bueno y lo malo, entre la eterna lucha entre el bien y el mal).

Además de la construcción semiótica de la imagen periodística, motivo de otro tipo de análisis, la relevancia y valor simbólico-ideológico de la foto de prensa está dada por el lugar y la forma que en el periódico ocupa. Aquí se consideran elementos principales tales como: el número de imágenes, si aparecen en primera plana o en interiores, si se ubican en páginas pares o impares, y por las relaciones establecidas entre foto/página, foto/pie de foto, y foto/texto escrito, así como por las zonas de preferencia de la página periodística en que se encuentren.

La tendencia de los encabezados del periódico, desde el día 2 hasta el día 17 de enero de 1994, fue la nota a ocho columnas que daba cuenta del levantamiento, intercalándose estas con declaraciones de los diferentes actores sociales involucrados activamente ante la situación. En los siguientes días se manejaron otras informaciones, algunas en relación con el suceso y otras más con la firme intención de minimizar el alcance que Chiapas iba teniendo en la realidad nacional.

$\mathrm{Al}$ respecto, es necesario considerar que a lo largo de ese año se presentaron otros sucesos que también conmocionaron la vida de la nación, sucesos tales como el asesinato del candidato priísta a la presidencia de la república Luis Donaldo Colosio (que mostró la descomposición existente dentro del sistema político mexicano); la designación del nuevo candidato por el mismo partido, Ernesto Zedillo (que produjo el rompimiento de los grupos de poder al interior de partido, crisis agudizada al ser él a la postre el actual presidente); el debate político-partidista ante las cámaras $\mathrm{d}$ televisión (inaugurando con ello una franca imitación, sistema norteamericano de hacer proselitismo tecnológico marketing político), con sus respectivas repercusiones en la prensa nacional; la participación de la selección nacional de futbol en el mundial 
USA-94 (que reafirmó los intereses económicos de la televisión privada en las distintas manifestaciones del mercado mediatizado para el pueblo); las elecciones presidenciales (y la ya considerada dosis de incredulidad); el asesinato del presidente del PRI, Ruiz Massieu (que nos enseño la conformación de las mafias de poder en la cúpula gobernante); y el crack económico (que es otra vuelta a la rueda de las crisis), de muchas más.

A pesar de que la lista es larga, no dejó de ser patente que la situación en Chiapas ocupó un lugar preponderante en los medios.

$\mathrm{Si}$ en un principio las relaciones foto/texto, foto/pie de foto y foto/página, respecto a Chiapas, fueron amplias, paulatinamente fueron modificándose hasta llegar al grado de dar más peso a los otros sucesos ya mencionados. En general, podemos decir que al inicio del conflicto las tres relaciones eran un $90 \%$ dentro de la sección "nacional" del periódico, sobresaliendo la relación foto/pie de foto, dado que "la imagen se ofrece ya estructurada profunda que contiene signos determinados, unidos por ciertas reglas coherentes de escritura visual, manteniendo un orden determinado, y que estimulan el proceso de interpretación del lector" (Vilches, 1987: 40).

Por su parte se privilegió la puesta de las imágenes tanto en las páginas impares como en las zonas de preferencia superior izquierda de las mismas, en virtud de que esos espacios son los más atendidos por el lector, por la manera cultural de lectura que se tiene en occidente. A todo lo que se lee de izquierda a derecha se le da un mayor peso y relevancia, y por ello, por ejemplo, la ubicación de los personajes principales al lado izquierdo en las fotografías de personalidades. los fotógrafos de La Jornada manejaron muy bien este factor, provocando que el simbolismo y la significación representado por el E.Z.L.N., en comparación con los otros actores, fuera mayor, sin importar por el momento si la perspectiva con que se mostraba fuera la correcta o no.

Cosa contraria sucedió con la imagen televisiva, donde las tomas y los encuadres trataron de mostrar una neutralidad simbólica y significativa, si no es que tendían francamente a minimizar la presencia del zapatismo. Una constante fue, por ejemplo, la de enfatizar la posición de los cadáveres al lado izquierdo, mientras que la de los zapatistas detenidos aparecían al lado derecho, lo que indica acusación y responsabilidad de los hechos.

Ante esta característica común por desvirtuar la realidad, Marcos optó por el veto a las empresas televisivas, incorporando una estrategia de comunicación diferente, estrategias que son las encargadas de que se permita "por una parte, observar la racionalidad de una representación y, por la otra, (que) conllevan mayores posibilidades pedagógicas para el diseño, a su vez, de estrategias alternativas de recepción con los diversos segmentos de la audiencia”. (Orozco, 1994: 4) 
Analicemos los hechos. Ante la deslegitimación del zapatismo por parte de la televisión, el E.Z.L.N. instauró su propia guerra de representaciones, la cual consistió, en una primera etapa, en dejarse entrevistar y fotografiar por los medios masivos, no con el afán vedetista, sino para decir a lo que salían, y según Marcos "no salimos a que nos mataran, sino a hacemos escuchar" (Marcos, 1994), lo que parece, sintetizar su estrategia permanente de comunicación, que a largo de este tiempo lo ha hecho casi indispensable en la vida cotidiana de nuestro país.

En una etapa posterior, como ya lo vimos, el aprovecha- miento de los comunicados dirigidos a audiencias específicas, interlocutores que dieron sentido a la lucha comunicativa del movimiento. Y por último, una tercera etapa que se conformó con la emisión de comunicados más puntuales sobre el proceso de negociación (Orozco, 1994: 7), proceso que terminó por legitimar la presencia social del E.Z.L.N. A esto se puede agregar el momento significativo en que se presentó el levantamiento y que, a su vez, se llena de momentos simbólicos para ambos polos del proceso: E.Z.L.N ./sociedad.

\section{El Momento Crucial}

Cuando hacemos por "naturalidad" votos por el cambio, propósitos de buena conducta, deseos de mejoramiento, tanto a título personal como a nivel social, de repente nos enfrentamos y confrontamos ante una realidad que va a alterar todo lo planeado en las cenas de Navidad y de fin de año, a una realidad que nos hará tomar conciencia del lugar que nos corresponde asumir como entes determinados socialmente.

Por su parte, como estudiosos de la comunicación, sabemos que en la prensa de los primeros dos ó tres días de enero, tradicionalmente, sólo encontramos noticias impactantes, amarillistas o de nota roja, dado que la inmovilidad nacional de esas fechas se vuelve únicamente asunto de promesas y buenos deseos que, también lo sabemos, tendrán como colofón la no bien recordada para el pueblo, "cuesta de enero".

Si no existen temas de interés y seguridad nacional, como lo fuera en 1995 la cuestión de los "errores gubernamentales" y la devaluación financiera de México, las páginas de los diarios se adelgazan palpablemente y muestran los pronósticos y augurio s que nos deparan para el año venidero, exceptuando la importancia de lo que en el ámbito deportivo pueda suceder.

Este no fue el caso de enero de 1994; mes en el que desde los primeros días nos enteramos de que la tan cacareada paz social se desvanecía y que los horrores de la guerra se hacían presentes y posibles en Chiapas. La realidad 
vista a través de los medios con la invasión a Panamá, con la guerra del Golfo Pérsico, con las guerrillas centroamericanas y con las atentados terroristas en diferentes partes del mundo, que siempre se veían como lejanas, se nos echaron encima con todo el rigor de seriedad y complejidad que ello implica.

Este momento crucial condujo a que el E.Z.L.N. no tuviera rival en el raiting de audiencia. Marcos, como vocero oficial del movimiento Zapatista, supo aprovechar y concretizar espléndidamente su surgimiento. Los canales de comunicación los encontró totalmente a su disposición, ya que los medios en esas fechas se hallan ávidos de encontrar noticias a ocho columnas.

Además, le dio relevancia extraordinaria al levantamiento con la instauración del comunicado como vehículo de información; vehículo que, por si mismo, ya es un documento que confronta la oficialidad desde la propia oficialidad, sin contar que ante la conciencia ciudadana, asusta e impone respeto. Recuérdese que las guerrillas centroamericanas así se condujeron, sólo que la diferencia en el caso de Marcos radicó en que los flujos fueron directos y firmados bajo el amparo de un Comité Indígena dirigente que encabezaba al Ejército Zapatista, y no únicamente de un grupo guerrillero, que intentara erigirse como caudillo.

En esos primeros días, "el acontecimiento se hizo de r preocupación nacional y de interés internacional. Desde el primer momento el Subcomandante buscó el contacto con la prensa, pero además de estar dispuesto para las entrevistas, comenzó de inmediato a producir los textos que sirvieron para sensibilizar a la sociedad y construir una imagen positiva del EZLN" (Fuego, 1994: 5).

Resulta claro que el Ejército Zapatista le ganó la guerra al gobierno mexicano en los medios. Pero no sólo eso se logró, también ahora sabemos con mayor precisión con qué tipo de medios contamos los mexicanos. La sociedad civil, desde entonces, busca referencias confiables para obtener información y mira con recelo y con crítica a ciertas publicaciones, así como a casi todos los medios electrónicos, en especial a la televisión.

Con este juego de letras e imágenes, se conformaron los elementos necesarios para construir el imaginario colectivo del movimiento Zapatista. Los medios, y particularmente la prensa, si bien cumplieron con su papel de ser instituciones que orientan la opinión pública, también lo es que se mostraron claramente como servidores, en su mayoría, de la clase pudiente.

$\mathrm{Al}$ respecto, no podemos negar tajantemente, ni sería i justo, que sí hubo algunos diarios y periodistas honestos que intentaron decir lo que realmente sucedía en aquellos momentos cruciales, por lo menos hasta donde lo permitió el poder, pero también debemos afirmar que es claro que la generalidad 
tendió hacia la justificación de las estructuras y las instituciones establecidas. Incluso se llegó al grado de argumentar que la votación masiva en las elecciones presidenciales pasadas, respondió al hecho del temor que la gente sentía de que la paz social se terminara de buenas a primeras.

Desde ese primero de enero, de la información se pasó a la opulencia informativa. Entre las ventajas de ello, está el hecho de que ciertos medios han tomado una posición de guardianes de la verdad (como el caso del diario El Tiempo de San Cristóbal de las Casas, que Marcos retomó como su medio oficial), buscando preservar el respeto a los derechos humanos, la información veraz, el registro histórico. También es ventaja el reconocimiento del problema y su tratamiento a viva voz en los medios de comunicación.

Los riesgos, por su parte, están implícitos en el ritual que en los últimos años repite la sociedad: que Chiapas pase a ser cosa juzgada, es decir, que una vez tratado y exhibido el problema en la radio, la prensa y la televisión, se vaya archivando en la memoria (Crovi, 1994:2).

\section{Recuento de la Presencia Zapatista en las Audiencias}

"Cuando ... busquen en la prensa lo que aconteció en el primer mes de guerra en Chiapas, encontrarán decenas de informaciones inconexas; algunas tramposas, noticias que no tienen explicación, contexto o seguimiento" (Riva Pala- cio 1994: 1). Lo dicho por este periodista crítico, sugiere el sentir general de los involucrados en los medios; lo que se produjo rayó muchas veces en la desinformación, pero no sólo por la actitud del informador o del medio, sino también porque los medios fueron tomados por sorpresa y sin prepa- ración para abordar un asunto tan delicado como el representado en la selva Lacandona.

Chiapas de nos presentó como un espejo de las deficiencias y los vicios. Si bien es cierto que los medios asumieron perfectamente su papel de eco del suceso, también lo es que no han asumido el papel de espacio donde se puedan dirimir diferencias políticas y tendencias de interpretación.

Es de común acuerdo que, como lo hemos visto más arriba, los medios se encargan de generar un tipo de conciencia, lo que aquí hemos denominado verosímil perfecto de la realidad, y que tiene que ver, en el caso concreto de la prensa en Chiapas, con la orientación que se constituyó expresa- mente en función de los grupos de poder, porque "la presentación del sistema simbólico noticia supone explicar formas de legitimación que los estados modernos auspician para mantener sus estructuras de dirección y de dominio" (Paoli, 1994: 112). 
La multiplicidad significante hace muy probable el perderse si uno no mantiene claro el sentido de su actuar, tal y como lo mostró el mar de tinta y papel que se trabajó durante el levantamiento.

Es posible reconocer una enorme supremacía de la televisión en su correspondencia con los otros medios; así lo manifestó la tendencia de la población en la encuesta elaborada por el diario Reforma en marzo de 1994, y en la cual se establece que la mayor información obtenida se presentó gracias a la televisión (82\%), seguida de la prensa y de la radio, con un 34\% y un 32\% respectivamente (Reforma, 1:/; 1994). Si bien no resulta del todo confiable una investigación echa al vapor, que contiene impresiones metodológicas como la citada, de cualquier manera es ilustrativa de que la población sí participó en consultar los medios para mantenerse al tanto de lo sucedido, reiterando que no evaluamos el sentido con el cual se manejo la información dentro de esos medios, cosa que es necesaria pero que rebasa las intenciones del presente trabajo.

Esta presencia social de los medios fue la encargada de construir ese verosímil perfecto de la realidad, que dependió en última instancia de la toma o no de conciencia que la gente pudo tener frente al significado del conflicto.

Particularmente la prensa y la televisión, en tanto circulación de imágenes, crearon las "normas que organizan la captación del mundo (y que) son indisociables del sistema de valores implícitos propios de una clase, de una profesión o de una capilla artística" (Bourdieu, 1989: 23).

Normas y valores que tienen que ver directamente con la construcción de ese imaginario colectivo que ha representado el movimiento Zapatista, y en especial la figura de Marcos; cosa que se hizo mito y significado patente (de acuerdo con la doble función que cumple el imaginario), cuando la población se concientizó y se adjudico el imaginario de "lo otro" manifestándolo en aquella frase que unió a la pluralidad cultural de este país: ¡todos somos marcos!.

\section{A Manera de Conclusión.}

Los dos tipos de guerra, la de las armas y la de la información, y los tres ejércitos enfrentados en Chiapas, el Zapatista, el mexicano y el de los medios, se combinan de tal modo que es posible abordar el fenómeno desde muy diversos ángulos. Pero es claro, al final de cuentas, que todos los protagonistas "han desplegado sus estrategias informativas, conscientes de que es frente a la audiencia donde tienen que realizar sus batallas cotidianas" (Orozco, 1994: $30)$. 
Parece que ahora somos más conscientes de las implicaciones que el actuar social presenta, como que adquirimos mayoría de edad como sociedad civil, y ya no es fácil que se nos manipule sin oponer resistencia. Ya lo decía Marcos al enviar sus mensajes y comunicados, que "al quitarse su propia máscara la sociedad mexicana se dará cuenta, con un impacto mayor, que la imagen que le habían vendido de sí misma es falsa y la realidad es bastante más aterradora de lo que suponía" (Marcos, 1994).

Lo imaginario resultó conformarse con el saber que existe un espejo de nuestra realidad, de nuestro significado en este contexto y ahora. Los medios se han encargado de incorporar ese verosímil perfecto de la realidad, para unos convertido en mito mientras que para otros conteniendo un significado profundo, en lo cotidiano, lugar donde se re-apropian y re-semantizan los significados de una gran pluriculturalidad nacional.

Ello ya influye en nuestra percepción de la vida. Ejerce influencia en el actuar diario y nos determina, de alguna manera, en nuestra forma de pensar.

\section{Bibliografía.}

Bourdieu, Pierre, 1989: La Fotografia un Arte Intermedio, México: Nueva Imagen.

Colombo, Eduardo, 1993: El Imaginario Social., Uruguay: Altamira.

Crovi, Delia, 1994: "Chiapas: del Silencio a la Opulencia Informativa" en Revista

Mexicana de Comunicación. Abril-Mayo de 1994, No. 34.

Eco, Umberto, 1988: De los Espejos y Otros Ensayos, España: Lumen.

Fuego, Emilio, 1994: "Los Zapatistas y la Opinión Publica” en Revista Mexicana de Comunicación Abril-Mayo de 1994, No. 34.

La Jornada. enero de 1994.

Marcos, 1992: "Chiapas: el Sureste en Dos Vientos, Una Tormenta y Una Profecia" Chiapas.

Marcos, 1993: "Declaración de la Selva Lacandona": Chiapas.

Marcos, 1994: "La Paz Social Solo Será si es Justa y Digna para Todos": Chiapas.

Marcos, 1994: “Quien Tiene que Pedir Perdón y Quien Puede Otorgarlo?, Chiapas.

Marcos, 1994: "Aqui Estamos Nosotros, los Muertos de Siempre, Murieron Otra Vez, Pero Ahora para Vivir', Chiapas. 
Orozco Gómez, Guillermo, 1994: "CHIAPAS: LA OTRA GUERRA, SUS PROTAGONISTAS Y LA TELEAUDIENCIA” Mimeo. Ponencia presentada en el Tercer Congreso Internacional de Pedagogia: De la Imagen: "La Realidad Inventada". La Coruña, julio 4-8 de 1994.

Paoli Bolio, Antonio, 1994: Recepción, Significado y Sistema Simbólico, México' Ed. Universidad Iberoamericana. Cuadernos del PROIICOM No. 6. Reforma. Marzo de 1994. Riva Palacio, Raymundo 1994: "La Prensa en Chiapas" en Revista Mexicana de Comunicación, Abril-Mayo de 1994, No. 34.

Trejo Delarbre, Raúl, 1994: Chiapas: La Comunicación Enmascarada. los Medios y el Pasamontañas. México: Diana.

Trejo Delarbre, Raúl, 1994: La Guerra de las Ideas, México: Diana. Uno más uno. enero de 1994.

Vilches, Lorenzo, 1987: Teoría de la Imagen Periodistica, España: Paidós. Colección Paidós Comunicación No. 25. 